Case Report

\title{
Prolonged Survival of a Refractory Acute Myeloid Leukemia Patient after a Third Hematopoietic Stem Cell Transplantation with Umbilical Cord Blood following a Second Relapse
}

\author{
Suk-young Lee, Naoki Kurita, Koichiro Maie, Masanori Seki, Yasuhisa Yokoyama, \\ Kazumi Suzukawa, Yuichi Hasegawa, and Shigeru Chiba \\ Department of Hematology, Faculty of Medicine, University of Tsukuba, Tennodai 1-1-1, Tsukuba, Ibaraki 305-8575, Japan \\ Correspondence should be addressed to Shigeru Chiba; schiba-t@md.tsukuba.ac.jp
}

Received 27 November 2013; Accepted 31 December 2013; Published 9 February 2014

Academic Editors: S. Langabeer, K. Nakase, and R. Tiu

Copyright (C) 2014 Suk-young Lee et al. This is an open access article distributed under the Creative Commons Attribution License, which permits unrestricted use, distribution, and reproduction in any medium, provided the original work is properly cited.

\begin{abstract}
Although hematopoietic stem cell transplantation (HSCT) has been considered to be the only way for potential cure of relapsed acute myeloid leukemia (AML), there has been no report on a third HSCT in patients with multiple relapsed AML. Here, we report a case of 53-year-old female who received a successful third allogeneic HSCT after relapse of AML following a second allogeneic HSCT. She was treated with a toxicity reduced conditioning regimen and received direct intrabone cord blood transplantation (CBT) using a single unit of 5/6 HLA-matched cord blood as a graft source. Graft-versus-host disease prophylaxis was performed with a single agent of tacrolimus to increase graft-versus-leukemia effect. She is in remission for 8 months since the direct intrabone CBT. This report highlights not only the importance of individually adjusted approach but also the need for further investigation on the role of HSCT as a treatment modality in patients with refractory or multiple relapsed AML.
\end{abstract}

\section{Introduction}

Decisions about how to treat patients with multiple relapsed AML are often based on the individual condition of each patient at relapse because no consensus on treatment of such patients has been established. Although there is no available clinical data as references in performing the third allogeneic HSCT currently, this has been performed sporadically at experienced transplant centers as one of options for treatment of patients with multiple relapsed AML, because the HSCT is regarded as the best way to achieve potential cure for refractory or relapsed AML. Here, we report a case who received the third allogeneic HSCT successfully without life-threatening complications and maintaining complete remission (CR) for 8 months.

\section{Case Report}

A female patient had been diagnosed with myelodysplastic syndrome, refractory anemia with excess blasts-2 (MDS, RAEB-2), at the age of 49 . The disease progressed to AML showing nearly $50 \%$ blasts in bone marrow (BM), when she received bone marrow transplantation (BMT) from an HLA-matched unrelated donor. Her conditioning regimen comprised $120 \mathrm{mg} / \mathrm{kg}$ cyclophosphamide and $12 \mathrm{~Gy}$ that was administered as six doses of fractionated total body irradiation. Tacrolimus and short-term methotrexate were used for graft-versus-host disease (GVHD) prophylaxis. Engraftment was achieved on posttransplant day 15 , and a BM examination on day 27 showed $>99 \%$ donor chimerism. The patient developed grade I acute GVHD (skin, stage 1).

Relapse of AML was diagnosed 14 months after the transplantation. A combination chemotherapy comprising idarubicin and Ara-C was ineffective, and 30\% leukemic blasts remained in the BM. A second HSCT was planned with cord blood as the graft source, because disease progression implied a need for an urgent care. A unit of 5/6 HLA-matched cord blood was transplanted after treatment with a preparation regimen comprising busulfan $(12.8 \mathrm{mg} / \mathrm{kg}$, i.v. $)$ and cyclophosphamide $(120 \mathrm{mg} / \mathrm{kg})$ at 16 months from the first transplantation. Mycophenolate mofetil and tacrolimus were used for GVHD prophylaxis. Engraftment was achieved on 


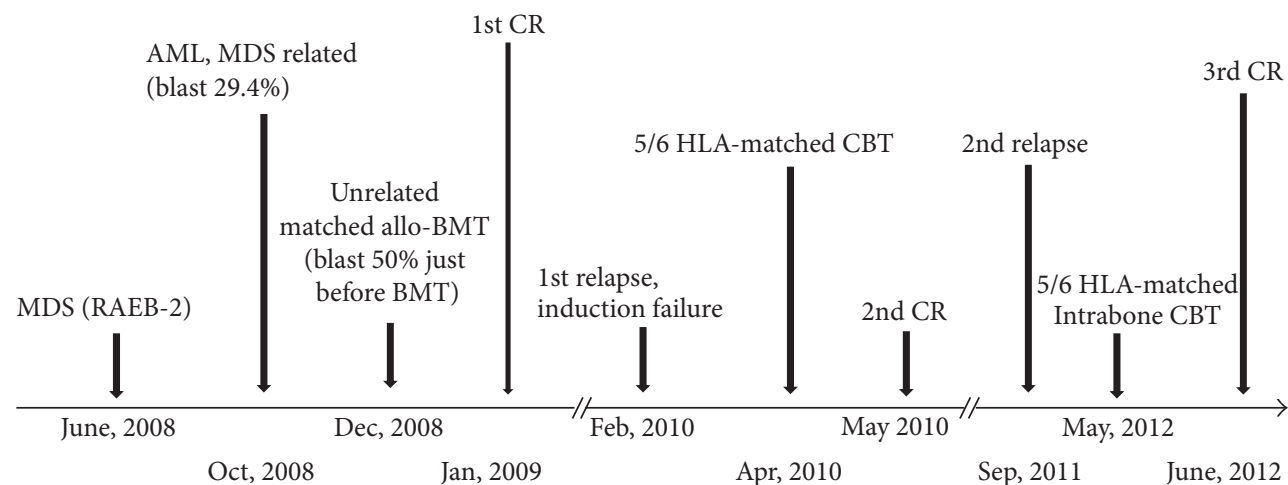

FIGURE 1: Time course of disease related to the HSCT. MDS, myelodysplastic syndrome; RAEB-2, refractory anemia with excess blast-2; allo-BMT, allogeneic bone marrow transplantation; CR, complete remission.

posttransplant day 17. On day 35, remission was achieved in the BM. The patient had grade II acute GVHD (skin, stage 3; gut, stage 1) and a limited type of chronic GVHD on the skin.

The patient experienced a relapse of AML 17 months after the CBT and showed 20\% leukemic blasts in the BM. The same karyotype as that in the initial AML was observed. A third HSCT using cord blood as the graft source was planned in non-CR status after treatment with a hypomethylating agent, azacitidine, $[1,2]$ at the age of 53 again, because the patient had no significant comorbidities. A unit of 5/6 HLAmatched cord blood was transplanted with a preparative regimen comprising fludarabine $\left(30 \mathrm{mg} / \mathrm{m}^{2} / \mathrm{d}\right.$ for 5 days); ranimustine (MCNU) $\left(150 \mathrm{mg} / \mathrm{m}^{2} / \mathrm{d}\right.$ for 2 days); melphalan $\left(140 \mathrm{mg} / \mathrm{m}^{2} / \mathrm{d}\right.$ for 1 day) $[3,4]$. Direct intrabone transplantation of a single unit of cord blood was performed $[5,6]$, with a total of $1 \times 10^{5} / \mathrm{kg} \mathrm{CD} 34$-positive cells and $3.2 \times 10^{7} / \mathrm{kg}$ nucleated cells administered 25 months after the second HSCT. A single immunosuppressive agent, tacrolimus, was used for GVHD prophylaxis to expect a graft-versus-leukemia (GVL) effect. Engraftment was achieved on posttransplant day 14, and $\mathrm{BM}$ remission was confirmed on day 28 . Acute skin stage 3 GVHD improved with steroid ointment treatment. BM examination 8 months after the direct intrabone CBT showed no evidence of leukemia recurrence (Figure 1).

\section{Discussion}

Here, we presented a case who successfully received a third allogeneic HSCT in her midfifties. Without any evidence from clinical trials, such decisions are made on a case-bycase basis and in accordance with an agreement between the transplant physicians in charge and the patient. Factors likely to have contributed to this case include early engraftment, minimum regimen-related toxicity (RRT), absence of serious infections, and mild GVHD that might have been associated with the GVL effect.

Although the decision of choosing an appropriate therapy is dependent on disease-related factors at relapse, HCST is known to be the only way to potentially cure relapsed AML. We presented an AML patient who achieved CR after the third allogeneic HSCT and maintained it for 8 months.
Despite a second relapse, poor cytogenetics (monosomy 17), and relatively old age, the reason for reduced RRT and lasting relapse-free survival in this patient could likely be attributed to several factors. The most important factor is believed to be a prolonged relapse-free period after the previous HSCT. CR duration has been recognized as the most dominant factor affecting outcomes of salvage therapy in relapsed AML $[7,8]$. In addition, the GVL effect is believed to have contributed to the extended period of relapse-free survival. It has been reported that CBT is beneficial in terms of reducing the frequency of GVHD while maintaining its GVL effect [9-12]. Furthermore, a study that presented the results of intrabone CBT showed an even lower frequency of GVHD with unchanged GVL effects [5]. In addition to these advantages, the dose of immunosuppressant was reduced early after transplantation, and only a single agent was used to increase the GVL effect in this patient. However, a longer follow-up period is required to prove the GVL effect, and the results of a large-scale prospective clinical trial should be waited to see the effect of intrabone CBT on the overall survival of AML patients. Direct intrabone CBT has also been reported as one way to overcome graft failure, one of the most serious complications of CBT in adult patients $[5,6]$. Relatively rapid engraftment with cord blood was observed in this case, similar to that previously reported [5], and this was believed to be one reason for reduced transplantation-related complications. The reduced toxicity conditioning regimen, which has been reported to induce high antileukemic activity in patients with active and advanced AML with reduced RRT $[3,4]$, is also considered to contribute to reduced complications.

In conclusion, we described a case with relapsed AML who received HSCT for the third time as a curative treatment. This report has important implications, because to the best of our knowledge, this is the first report of a third HSCT in an AML patient, although it might be difficult to conclude that HSCT is a feasible treatment for most patients with refractory or relapsed AML based on only a single case. This report also highlights the need for further studies on the outcomes and prognosis-predicting factors in performing HSCT in multiple relapsed AML patients to reach a treatment consensus. 


\section{Conflict of Interests}

The authors declare that there is no conflict of interests regarding the publication of this paper.

\section{References}

[1] T. Graef, A. Kuendgen, R. Fenk, F. Zohren, R. Haas, and G. Kobbe, "Successful treatment of relapsed AML after allogeneic stem cell transplantation with azacitidine," Leukemia Research, vol. 31, no. 2, pp. 257-259, 2007.

[2] A. Czibere, I. Bruns, N. Kröger et al., "5-Azacytidine for the treatment of patients with acute myeloid leukemia or myelodysplastic syndrome who relapse after allo-SCT: a retrospective analysis," Bone Marrow Transplantation, vol. 45, no. 5, pp. 872876, 2010.

[3] R. Wäsch, S. Reisser, J. Hahn et al., "Rapid achievement of complete donor chimerism and low regimen-related toxicity after reduced conditioning with fludarabine, carmustine, melphalan and allogeneic transplantation," Bone Marrow Transplantation, vol. 26, no. 3, pp. 243-250, 2000.

[4] R. Marks, K. Potthoff, J. Hahn et al., "Reduced-toxicity conditioning with fludarabine, BCNU, and melphalan in allogeneic hematopoietic cell transplantation: particular activity against advanced hematologic malignancies," Blood, vol. 112, no. 2, pp. 415-425, 2008.

[5] F. Frassoni, F. Gualandi, M. Podestà et al., "Direct intrabone transplant of unrelated cord-blood cells in acute leukaemia: a phase I/II study," The Lancet Oncology, vol. 9, no. 9, pp. 831-839, 2008.

[6] M. Okada, S. Yoshihara, K. Taniguchi et al., "Intrabone marrow transplantation of unwashed cord blood using reducedintensity conditioning treatment: a phase I study," Biology of Blood and Marrow Transplantation, vol. 18, no. 4, pp. 633-639, 2012.

[7] D. A. Breems, W. L. J. van Putten, P. C. Huijgens et al., "Prognostic index for adult patients with acute myeloid leukemia in first relapse," Journal of Clinical Oncology, vol. 23, no. 9, pp. 19691978, 2005.

[8] P. Chevallier, M. Labopin, P. Turlure et al., "A new leukemia prognostic scoring system for refractory/relapsed adult acute myelogeneous leukaemia patients: a GOELAMS study," Leukemia, vol. 25, no. 6, pp. 939-944, 2011.

[9] R. P. Howrey, P. L. Martin, T. Driscoll et al., "Graft-versus-leukemi-induced complete remission following unrelated umbilical cord blood transplantation for acute leukemia," Bone Marrow Transplantation, vol. 26, no. 11, pp. 1251-1254, 2000.

[10] M. J. Laughlin, M. Eapen, P. Rubinstein et al., "Outcomes after transplantation of cord blood or bone marrow from unrelated donors in adults with leukemia," The New England Journal of Medicine, vol. 351, no. 22, pp. 2265-2275, 2004.

[11] V. Rocha, J. Cornish, E. L. Sievers et al., "Comparison of outcomes of unrelated bone marrow and umbilical cord blood transplants in children with acute leukemia," Blood, vol. 97, no. 10, pp. 2962-2971, 2001.

[12] V. Rocha, M. Labopin, G. Sanz et al., "Transplants of umbilicalcord blood or bone marrow from unrelated donors in adults with acute leukemia," The New England Journal of Medicine, vol. 351, no. 22, pp. 2276-2285, 2004. 


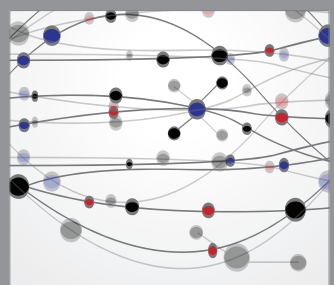

The Scientific World Journal
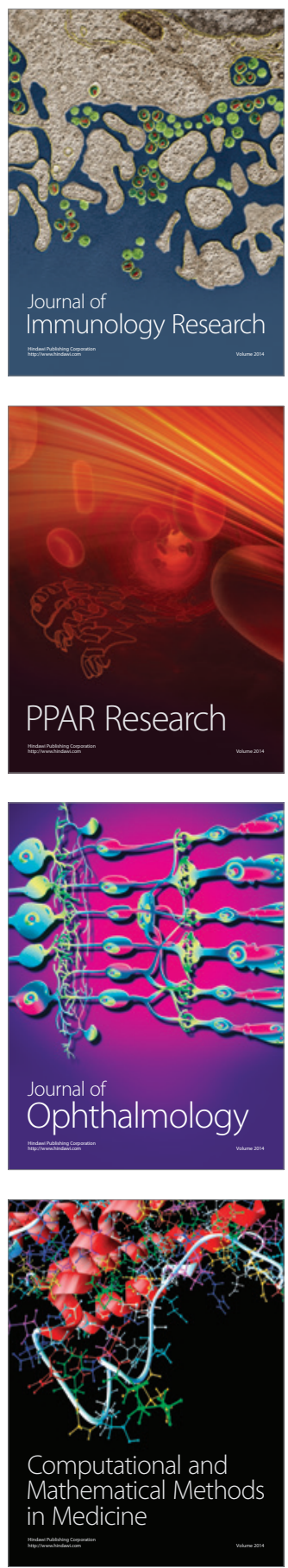

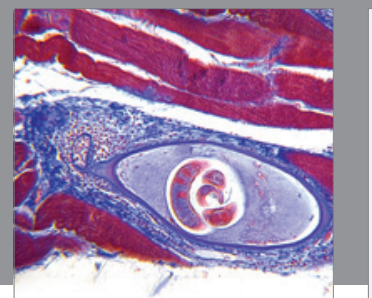

Gastroenterology

Research and Practice
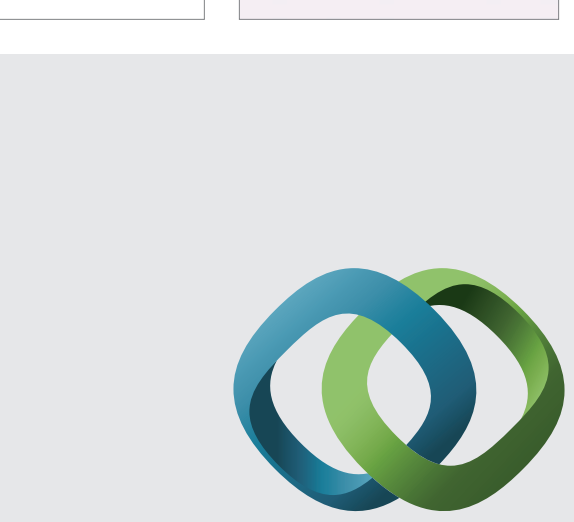

\section{Hindawi}

Submit your manuscripts at

http://www.hindawi.com
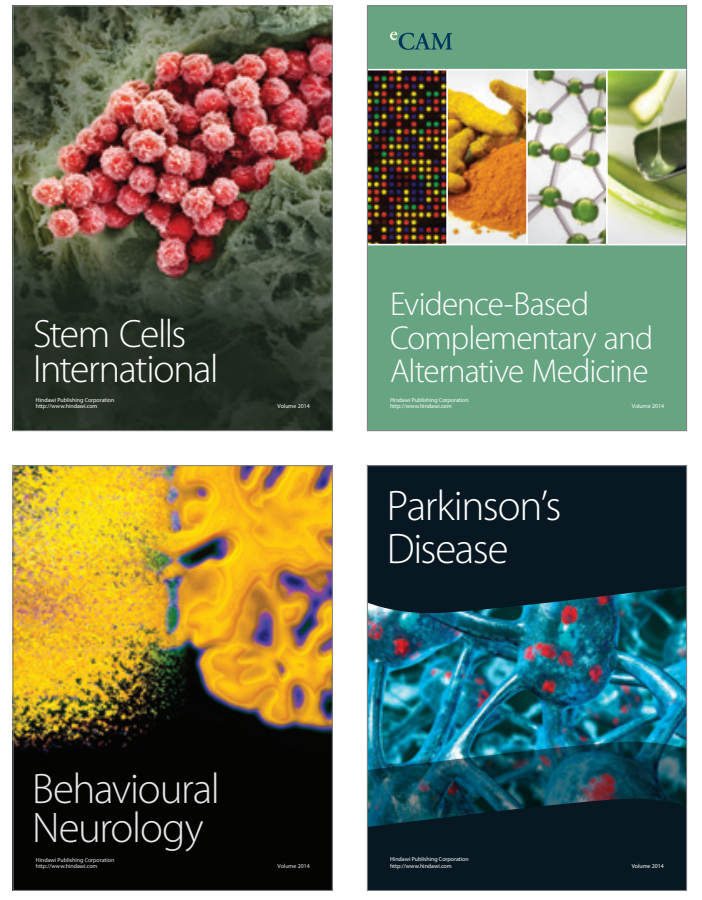
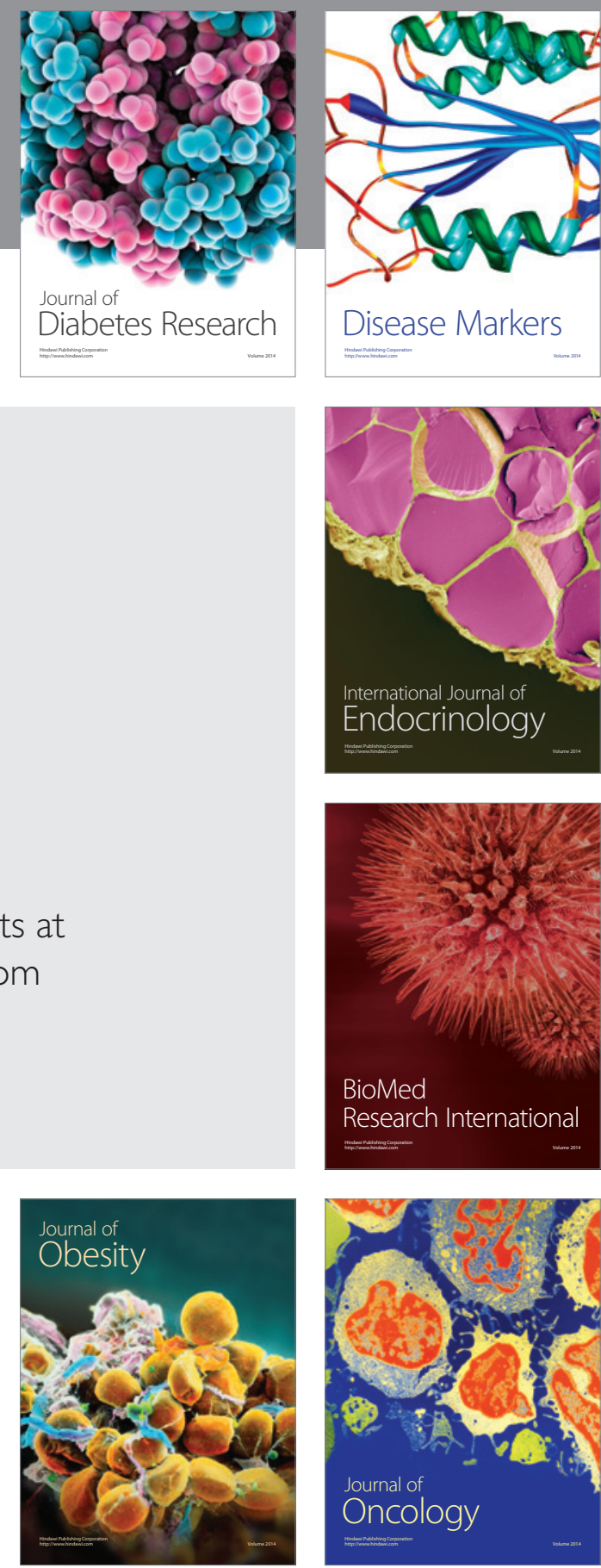

Disease Markers
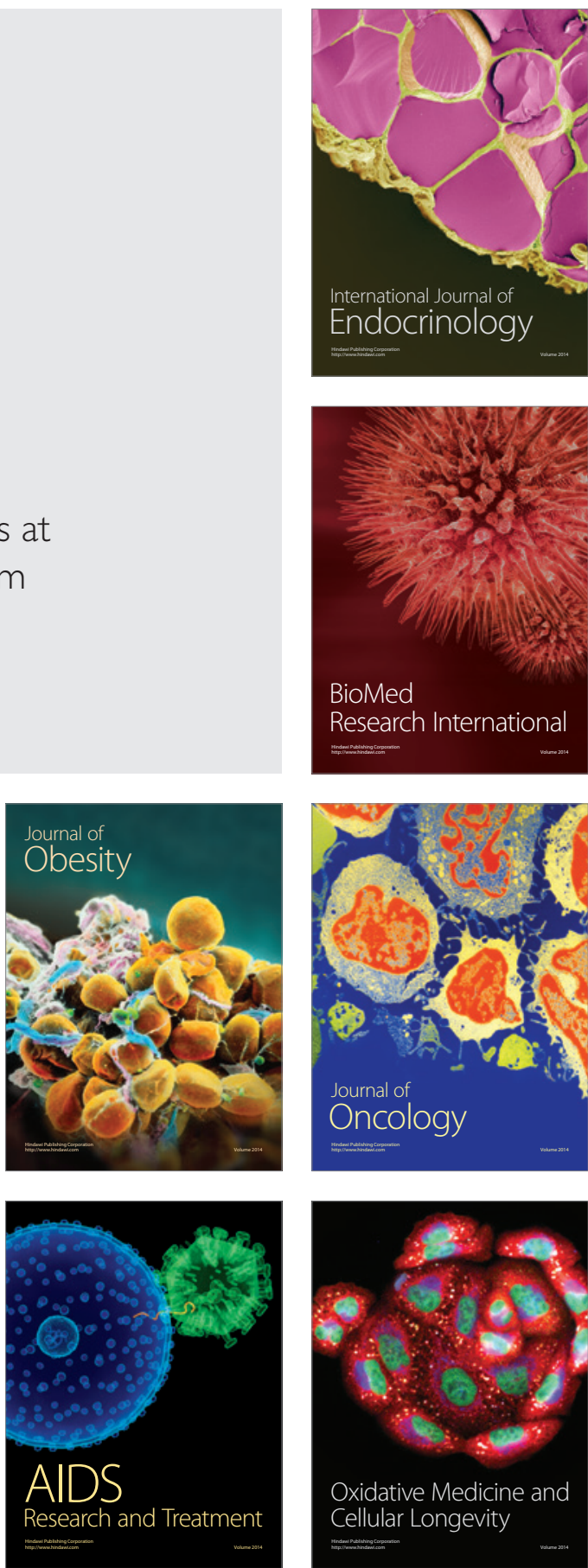